\title{
8th Pacific Regional Wood Anatomy Conference/ Annual Meeting of International Academy of Wood Science (IAWS), Nanjing Forestry University, Nanjing, China October 17-22, 2013
}

\author{
John R. Barnett
}

(C) Springer-Verlag Berlin Heidelberg 2013

This year's plenary meeting of the Academy was held jointly with the International Association of Wood Anatomists (IAWA) Pacific Region in Nanjing, China. It accords with the IAWS policy of linking its meetings with other wood science meetings worldwide. The meeting was attended by over 230 delegates, 83 of whom were from outside China.

The Academy was welcomed to Nanjing by Xu Ming, the Vice Governor of Jiangsu province and Professor Jiang Zehui, Director General and Principal Scientist at the International Center for Bamboo and Rattan (ICBR), Beijing, China.

More than 100 oral presentations and 80 posters were presented on a wide range of wood anatomy and wood science topics. The Academy Lecture was presented by Professor Pieter Baas from Leiden University and the Naturalis Biodiversity Center in Leiden, the Netherlands, on wood anatomical diversity. Professor Baas is well known as an outstanding researcher, who has provided technical advances in wood anatomy and has been a long-time leader in IAWA. He was also instrumental in developing the former IAWA Bulletin into the high-quality IAWA Journal: the only one specializing in wood anatomy.

During the conference, President Salmén presented the IAWS Distinguished Service Award to Professor Jiang Zehui, who also made a presentation about the ICBR's research priorities and the use of bamboo. Professor Jiang has been a driving force in all areas of wood science and especially in advancing international programs throughout the world.

Also presented was this year's PhD Award, which went to Dr. Sergio Sanabria from ETH, Zurich, Switzerland, for his work in nondestructive testing of bonding quality in timber composites.

The meeting concluded with an IAWS business meeting followed by the Fellows Dinner. Plans for the 2014 meeting are in hand and details will be announced in due course.

More specific information can be obtained on the conference website: http://8thprwac.njfu.edu.cn/. 